\title{
Inherited DNA Repair Gene Mutations in Men with Lethal Prostate Cancer
}

\author{
Tommi Rantapero ${ }^{1}$, Tiina Wahlfors ${ }^{1}$, Anna Kähler ${ }^{2}$, Christina Hultman ${ }^{2}$, Johan Lindberg ${ }^{2}$, \\ Teuvo L. J. Tammela ${ }^{1}$, Matti Nykter ${ }^{1}$, Johanna Schleutker ${ }^{3,4}$ and Fredrik Wiklund ${ }^{2, *} *$ (D) \\ 1 Faculty of Medicine and Health Technology, Prostate Cancer Research Center, Tampere University, \\ 33100 Tampere, Finland; tommi.rantapero@tuni.fi (T.R.); tiina.wahlfors@veripalvelu.fi (T.W.); \\ teuvo.tammela@pshp.fi (T.L.J.T.); matti.nykter@tuni.fi (M.N.) \\ 2 Department of Medical Epidemiology and Biostatistics, Karolinska Institutet, 17177 Stockholm, Sweden; \\ anna.kahler@ki.se (A.K.); christina.hultman@ki.se (C.H.); johan.lindberg@ki.se (J.L.) \\ 3 Institute of Biomedicine, University of Turku, 20014 Turku, Finland; johanna.schleutker@utu.fi \\ 4 Department of Medical Genetics, Genomics, Laboratory Division, Turku University Hospital, \\ 20521 Turku, Finland \\ * Correspondence: fredrik.wiklund@ki.se; Tel.: +46-852483979
}

Received: 19 February 2020; Accepted: 13 March 2020; Published: 14 March 2020

check for updates

\begin{abstract}
Germline variants in DNA repair genes are associated with aggressive prostate cancer (PrCa). The aim of this study was to characterize germline variants in DNA repair genes associated with lethal $\mathrm{PrCa}$ in Finnish and Swedish populations. Whole-exome sequencing was performed for 122 lethal and 60 unselected PrCa cases. Among the lethal cases, a total of 16 potentially damaging protein-truncating variants in DNA repair genes were identified in 15 men (12.3\%). Mutations were found in six genes with CHEK2 (4.1\%) and ATM (3.3\%) being most frequently mutated. Overall, the carrier rate of truncating variants in DNA repair genes among men with lethal PrCa significantly exceeded the carrier rate of $0 \%$ in 60 unselected PrCa cases $(p=0.030)$, and the prevalence of $1.6 \%(p<0.001)$ and $5.4 \%(p=0.040)$ in Swedish and Finnish population controls from the Exome Aggregation Consortium. No significant difference in carrier rate of potentially damaging nonsynonymous single nucleotide variants between lethal and unselected PrCa cases was observed $(p=0.123)$. We confirm that DNA repair genes are strongly associated with lethal $\mathrm{PrCa}$ in Sweden and Finland and highlight the importance of population-specific assessment of variants contributing to PrCa aggressiveness.
\end{abstract}

Keywords: prostate cancer; DNA repair genes; lethal cancer

\section{Introduction}

Prostate cancer ( $\mathrm{PrCa})$, the most common male cancer worldwide, has a wide spectrum of clinical behavior that ranges from decades of indolence to rapid metastatic progression and lethality [1]. PrCa is also among the most heritable human cancers, with $57 \%$ of the interindividual variation in risk attributed to genetic factors [2]. Genome-wide association studies (GWAS) have thus far confirmed $\sim 170$ susceptibility loci that account for over $30 \%$ of the familial relative risk [3]. However, the risk variants identified using case-control designs show little or no ability to discriminate between indolent and fatal forms of this disease [4]. Therefore, studies contrasting patients with more and less aggressive disease and those exploring associations with disease progression and prognosis should be more effective at detecting genetic risk factors for aggressive PrCa with prognostic potential. 
Inherited and acquired defects in DNA repair genes are a common hallmark of cancer and, to date, numerous inherited DNA repair gene mutations that increase cancer risk has been identified [5]. In particular, mutations in $B R C A 1$ and $B R C A 2$ genes, both associated with several DNA repair pathways, confer a strikingly increased risk of breast and ovarian cancer [6]. In addition, it is now recognized that the downregulation of DNA repair response is necessary for tumor progression into a more aggressive phenotype [5]. Accumulating evidence suggests that pathogenic germline variants in known cancer-predisposing genes such as BRCA2 can increase the risk of developing PrCa, especially the more aggressive form of the disease [7]. Likewise, several other genes that were initially implicated as high-risk genes in cancers other than PrCa, such as CHEK2 and BRIP1, have subsequently been shown to increase the risk of PrCa as well [8-10]. Recent studies have reported a high carrier rate of inherited DNA repair gene mutations among men with metastatic PrCa (11.8\%), significantly exceeding the prevalence (4.6\%) among men with localized PrCa [11].

In this study, we evaluated germline variants of DNA repair genes in men who died of PrCa. The aim of our study was to identify and investigate the frequency of pathogenic germline variants in men with the lethal form of the disease.

\section{Materials and Methods}

\subsection{Study Subjects}

Genomic DNA from a total of 122 lethal PrCa patients was collected from an ongoing collection of Finnish PrCa patients (TAMPERE, $n=47$ ) and the Swedish Cancer of Prostate in Sweden (CAPS, $n=75$ ) study. To create an extremely aggressive phenotype, the inclusion criterion for lethal PrCa cases was that the patient should have died due to PrCa before the age of 65. All of the Finnish patients were recruited in the Pirkanmaa Hospital District as part of a hereditary PrCa family collection or through collection of sporadic cases treated at the regional hospital [12]. The Swedish CAPS study is a population-based case-control study that enrolled participants between 2001 and 2003 [13]. An additional 70 PrCa patients from the TAMPERE population, not selected for disease aggressiveness or young age at death (hereby denoted unselected cases), with whole-exome sequencing data available were also included to contrast against the lethal cases. Clinical information, such as clinical stage, pathologic grade, nodal or distant metastases, and diagnostic serum levels of PSA and vital status, including cause of death, was obtained through medical records and national cancer registries. All samples were collected with written and signed informed consent. The project was approved by the research ethics committee at Pirkanmaa Hospital District (R03203), the Finnish National Supervisory Authority of Welfare and Health (5569/32/300/05) and by the ethics committees at the Karolinska Institutet (04-449/4 and 06-381/32).

\subsection{Sample Preparation, Sequencing and Genotyping}

Genomic DNA was extracted from whole blood by standard methods. For the 122 lethal cases, exome capture was performed using Agilent SureSelect Human All Exon $50 \mathrm{M}$ kit (Agilent Technologies, Inc., Santa Clara, CA, USA) according to standard protocol and sequenced at the Science for Life laboratory (Stockholm, Sweden). Of the 70 unselected cases 25 samples were sequenced by BGI Tech Solutions (Hong Kong, China) with exome capture performed by the SureSelect Human All Exon 50 M kit while the remaining 45 unselected cases were sequenced at Mayo Clinic, Rochester, MN, USA with exome capture performed using Agilent SureSelect Human All Exon 50Mb or V4+UTR kits. At each site samples were sequenced using the Illumina Hiseq (Illumina, Inc, San Diego, CA, USA). 


\subsection{Sample Quality Control and Variant Calling}

The reads were aligned against the hy19 genome build retrieved from UCSC using BWA [14]. BEDtools [15] was used to calculate the genome-wide coverage for each sample where samples with less than $30 \%$ of bases covered by at least 20 reads were excluded. The PCR duplicates were marked using PICARD [16], and the base score recalibration was performed using GATK [17]. Subsequently, GATK was used to call the variants and genotypes following the GATK best practices protocol for germline exome-sequencing data $[18,19]$. The candidate false-positive variants were initially filtered using the variant quality score recalibration procedure using the tranche threshold 99.0. Furthermore, variants having an allele fraction of less than 0.3 or a coverage of less than 12 were filtered out. Finally, variants with a readPosRankSum less than or equal to -1.7 were discarded. The variants were annotated using ANNOVAR [20].

\subsection{Variant Prioritization}

Variants found in 175 DNA repair genes [21-23] were selected for further analysis. To prioritize variants for validation, we utilized a similar approach to that introduced by Mijuskovic and coworkers [7]. The intergenic and common (minor allele frequency $>0.01$ ) variants were filtered out. The remaining rare variants were classified into two categories: potentially damaging and neutral. The potentially damaging variants were further classified into two categories (Tier 1 and Tier 2) based on their impact. The classification was performed utilizing a database of reported associations of variants to clinical phenotypes (ClinVar) provided by ANNOVAR and two tools for pathogenicity prediction, CADD [24] and REVEL [25], of which the latter is specifically designed for discovery of rare deleterious variants. Moreover, the known protein domains from the UniProt [26] database were utilized to assess the pathogenicity of protein truncating variants.

Those variants that are reported as likely benign or benign in ClinVar were classified as neutral. Protein truncating variants (stopgain, frameshift indels or splicing site altering variants) were classified as Tier 1 variants if they had a CADD phred score $\geq 20$. Furthermore, the variants were required to be reported to be pathogenic or likely pathogenic by the ClinVar database or alternatively known to affect a protein domain reported in Uniprot (e.g., occurring before or within a protein domain). All nonsynonymous single nucleotide variants (missense variants) reported to be pathogenic or likely pathogenic by ClinVar or had a CADD phred score $\geq 20$ and REVEL score $\geq 0.75$ were classified as Tier 2 variants. The same prioritization criteria were applied to both case cohorts. The full workflow including details of the sequencing data analysis is illustrated in Figure 1. 


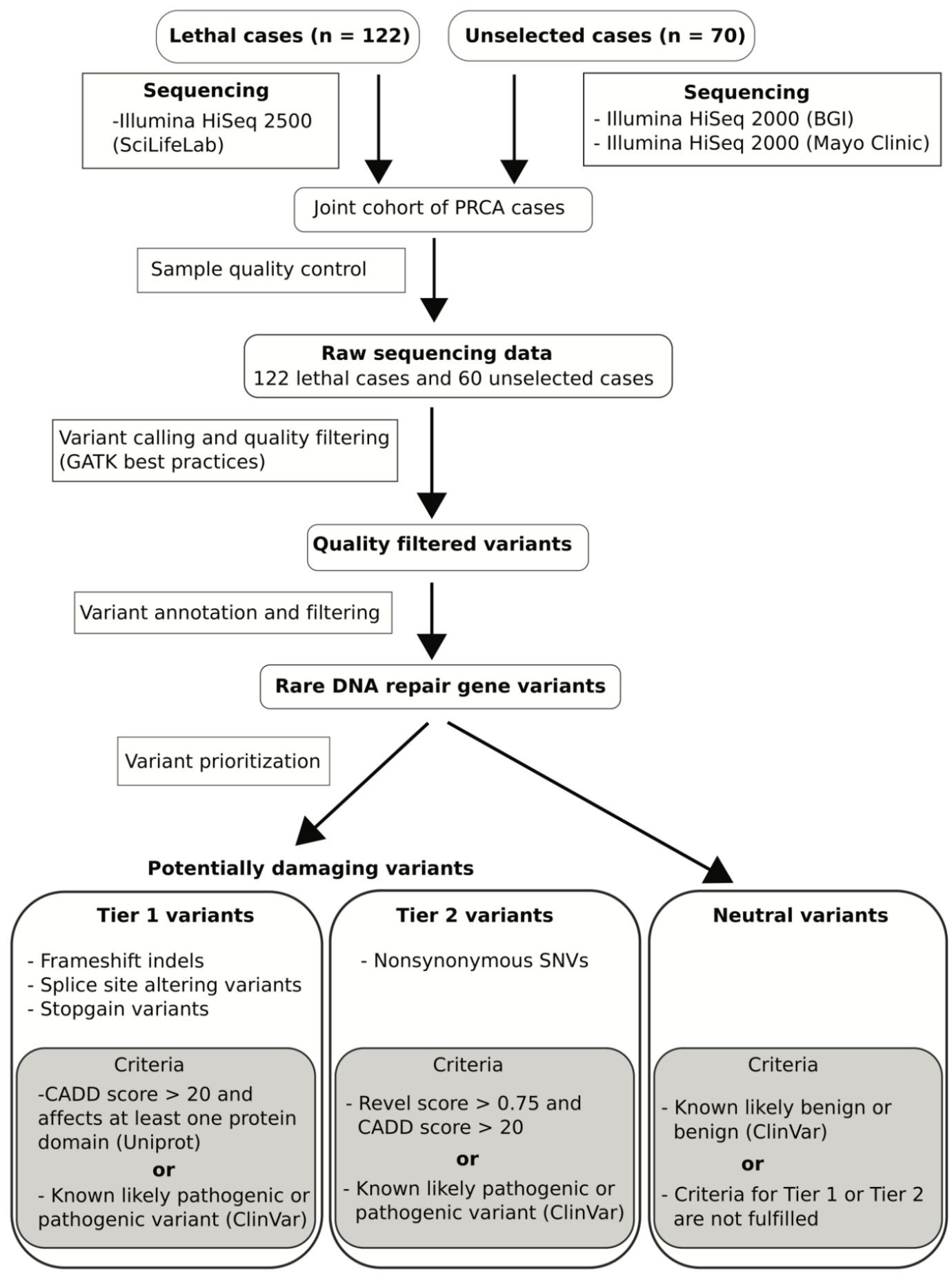

Figure 1. Flow chart describing processing of whole exome sequencing, quality control, variant calling and annotation, and variant prioritizing. PRCA: prostate cancer; ClinVar: database of reported associations of variants to clinical phenotypes; CADD: combined annotation dependent depletion; Revel: rare exome variant ensemble learner.

\subsection{Population Frequencies}

To explore the expected population allele frequencies of pathogenic variants in the discovered DNA repair genes, we extracted data from two subsets of the Exome Aggregation Consortium (ExAC) browser [27], one set comprising 6192 Swedish population controls and one set comprising 3307 Finnish individuals unselected for cancer history. Full details of the data processing, variant calling 
and resources have been described previously [27]. Variant prioritization among these population controls was performed by the same filtering algorithm as described above for the PrCa cases.

\subsection{Statistical Analysis}

Baseline characteristics were described using the median (interquartile range [IQR]) for continuous variables and absolute and relative frequencies for categorical variables. The frequency of potentially damaging DNA repair gene mutation carriers among the lethal PrCa patients was compared to the frequency in unselected PrCa patients and the two control populations with the use of a two-sided Fisher's exact test. For the control populations, the frequency of mutation carriers in a specific gene was calculated on the basis of the total number of persons for whom sequence coverage was adequate for the given allele, under the assumption that each individual carried at most one deleterious mutation in the explored gene. This assumption may have introduced a slight overestimation in the carrier frequency in the control populations. In all analyses, Tier 1 and Tier 2 mutations were assessed separately. No adjustment was made for multiple testing, and $p$ values less than 0.05 were considered to indicate statistical significance.

\section{Results}

We performed a comprehensive genetic assessment of DNA repair genes in 122 PrCa cases selected for very aggressive disease and $70 \mathrm{PrCa}$ cases unselected for disease aggressiveness. After exclusion of 10 samples due to insufficient sequencing coverage, 122 lethal cases and 60 unselected cases remained for analysis (Figure 1)-see Table 1 for the clinical characteristics of case cohorts.

Table 1. Clinical characteristics of patients.

\begin{tabular}{|c|c|c|}
\hline & $\begin{array}{l}\text { Lethal PrCa } \\
\qquad(n=122)\end{array}$ & $\begin{array}{c}\text { Unselected } \\
\text { PrCa }(n=60)\end{array}$ \\
\hline Age at diagnosis, median (IQR) & $57.0(55.1-58.2)$ & $66.5(57.8-73.8)$ \\
\hline Diagnostic PSA level (ng/mL), median (IQR) & $56.2(17.9-247.2)$ & $10.8(7.0-18.8)$ \\
\hline \multicolumn{3}{|l|}{ Clinical T-stage, $n(\%)$} \\
\hline $\mathrm{TX}$ & $2(1.8)$ & $0(0.0)$ \\
\hline $\mathrm{T} 1$ & $8(7.3)$ & $20(38.5)$ \\
\hline $\mathrm{T} 2$ & $18(16.4)$ & $15(28.8)$ \\
\hline T3 & $61(55.5)$ & $15(28.8)$ \\
\hline $\mathrm{T} 4$ & $21(19.1)$ & $2(3.8)$ \\
\hline NA & 12 & 8 \\
\hline \multicolumn{3}{|l|}{ Clinical N-stage, $n(\%)$} \\
\hline NX & $86(78.2)$ & $52(100.0)$ \\
\hline No & $9(8.2)$ & $0(0.0)$ \\
\hline N1 & $15(13.6)$ & $0(0.0)$ \\
\hline NA & 12 & 8 \\
\hline \multicolumn{3}{|l|}{ Clinical M-stage, $n(\%)$} \\
\hline $\mathrm{MX}$ & $11(10.0)$ & $14(26.9)$ \\
\hline M0 & $45(40.9)$ & $32(61.5)$ \\
\hline M1 & $54(49.1)$ & $6(11.5)$ \\
\hline NA & 12 & 8 \\
\hline \multicolumn{3}{|l|}{ Gleason score, $n(\%)$} \\
\hline $2-6$ & $11(10.5)$ & $16(47.1)$ \\
\hline 7 & $36(34.3)$ & $7(20.6)$ \\
\hline $8-10$ & $58(55.2)$ & $11(32.4)$ \\
\hline NA & 17 & 26 \\
\hline Death due to $\operatorname{PrCa}, \mathrm{n}(\%)$ & $122(100.0)$ & $15(25.0)$ \\
\hline Age at death, median (IQR) & $60.0(57.9-62.9)$ & $79.5(69.5-84.5)$ \\
\hline
\end{tabular}

PrCa: prostate cancer; PSA: prostate-specific antigen; NA: not available. 
In total, 22,850,167 variants were discovered and variant prioritization yielded 31 potentially damaging variants distributed across 17 DNA repair genes among the cases (Table 2).

Table 2. Potentially damaging mutations identified in men with lethal prostate cancer.

\begin{tabular}{|c|c|c|c|c|c|c|c|c|c|}
\hline Gene & RSID & Type & Ref & Alt & $\begin{array}{l}\text { Protein } \\
\text { Change }\end{array}$ & ClinVar & CADD/REVEL & MAF & Tier \\
\hline ATM & rs758081262 & stopgain & $\mathrm{C}$ & $\mathrm{T}$ & Q852X & 5 & $35 /-$ & $2.5 \times 10^{-5}$ & 1 \\
\hline ATM & rs761486324 & $\begin{array}{l}\text { frameshift } \\
\text { ins }\end{array}$ & - & TG & H1082fs & - & $-/$ & - & 1 \\
\hline ATM & rs767099464 & $\begin{array}{c}\text { frameshift } \\
\text { del }\end{array}$ & C & - & H1083fs & - & $-/-$ & - & 1 \\
\hline ATM & rs769142993 & missense & G & $\mathrm{C}$ & A2524P & 4 & $31 / 0.89$ & $2.5 \times 10^{-5}$ & 2 \\
\hline ATM & - & $\begin{array}{l}\text { frameshift } \\
\text { del }\end{array}$ & AGTAG & - & S2611fs & - & $-/-$ & - & 1 \\
\hline ATM & rs753961188 & $\begin{array}{l}\text { frameshift } \\
\text { ins }\end{array}$ & - & $\mathrm{T}$ & L2885fs & 5,4 & $-/$ & $4.2 \times 10^{-5}$ & 1 \\
\hline ATM & rs376676328 & missense & A & G & R2912G & 3 & $29 / 0.88$ & $3.0 \times 10^{-4}$ & 2 \\
\hline BRCA1 & rs41293459 & missense & C & $\mathrm{T}$ & R1699Q & $5,4,3$ & $35 / 0.79$ & $2.5 \times 10^{-5}$ & 2 \\
\hline CHEK2 & rs555607708 & $\begin{array}{c}\text { frameshift } \\
\text { del }\end{array}$ & G & - & T367fs & 5 & $-/-$ & $1.8 \times 10^{-3}$ & 1 \\
\hline CHEK2 & rs137853007 & missense & G & A & R145W & 5,4 & $33 / 0.81$ & $3.3 \times 10^{-5}$ & 2 \\
\hline CHEK2 & rs730881700 & $\begin{array}{l}\text { frameshift } \\
\text { ins }\end{array}$ & - & $\mathrm{T}$ & E457fs & 5,4 & $-/-$ & $5.0 \times 10^{-5}$ & 1 \\
\hline CHEK2 & rs28909982 & missense & $\mathrm{T}$ & $\mathrm{C}$ & R117G & 5,4 & $27 / 0.93$ & $1.0 \times 10^{-4}$ & 2 \\
\hline ERCC3 & rs753182861 & $\begin{array}{l}\text { frameshift } \\
\text { del }\end{array}$ & $\mathrm{T}$ & - & Q586fs & - & $-/$ & $2.0 \times 10^{-4}$ & 1 \\
\hline ERCC3 & rs145267069 & missense & A & G & F297S & - & $30 / 0.82$ & $2.5 \times 10^{-5}$ & 2 \\
\hline FAN1 & rs778927800 & missense & G & A & R749Q & - & $34 / 0.89$ & $8.3 \times 10^{-6}$ & 2 \\
\hline FANCM & rs147021911 & stopgain & C & $\mathrm{T}$ & Q1701X & 4 & $35 / 0.12$ & $1.3 \times 10^{-3}$ & 1 \\
\hline HLTF & rs184046773 & missense & $\mathrm{C}$ & $\mathrm{T}$ & G1886A & - & $33 / 0.81$ & $2.0 \times 10^{-4}$ & 2 \\
\hline MRE11A & rs372000848 & missense & G & A & R305W & 4,3 & $33 / 0.85$ & $5.0 \times 10^{-5}$ & 2 \\
\hline MUTYH & rs34126013 & missense & G & A & R238W & 5,4 & $33 / 0.79$ & $9.2 \times 10^{-5}$ & 2 \\
\hline NEIL1 & rs5745906 & missense & G & A & G169D & - & $27 / 0.86$ & $1.3 \times 10^{-3}$ & 2 \\
\hline NTHL1 & rs150766139 & stopgain & G & A & Q90X & 5,3 & $35 /-$ & $1.5 \times 10^{-3}$ & 1 \\
\hline POLG & rs761584617 & missense & G & A & A1115V & - & $23 / 0.80$ & $2.5 \times 10^{-5}$ & 2 \\
\hline POLG & rs113994097 & missense & C & G & W748S & 5,3 & $33 / 0.91$ & $8.0 \times 10^{-4}$ & 2 \\
\hline POLG & rs113994096 & missense & G & A & P587L & 5,3 & $28 / 0.80$ & $1.7 \times 10^{-3}$ & 2 \\
\hline POLG & rs121918052 & missense & C & G & Q497H & 5,3 & $26 / 0.71$ & $2.0 \times 10^{-4}$ & 2 \\
\hline POLL & rs139871590 & missense & $\mathrm{C}$ & $\mathrm{T}$ & G356S & - & $34 / 0.83$ & $1.0 \times 10^{-3}$ & 2 \\
\hline RAD18 & rs138830303 & stopgain & $\mathrm{T}$ & A & K197X & - & $36 /-$ & $1.0 \times 10^{-4}$ & 1 \\
\hline RECQL & rs149937760 & missense & $\mathrm{C}$ & $\mathrm{T}$ & C414Y & - & $33 / 0.84$ & $2.0 \times 10^{-4}$ & 2 \\
\hline RECQL5 & rs768705080 & missense & $\mathrm{T}$ & G & Y362S & - & $32 / 0.76$ & $8.2 \times 10^{-6}$ & 2 \\
\hline ТP53 & rs876660754 & missense & $\mathrm{C}$ & $\mathrm{T}$ & V173M & 5,4 & $28 / 0.89$ & - & 2 \\
\hline TP53 & rs779000871 & missense & G & A & $\mathrm{T} 170 \mathrm{M}$ & 3 & $24 / 0.87$ & $8.2 \times 10^{-5}$ & 2 \\
\hline
\end{tabular}

Note: ClinVar clinical significance score defines as: $5=$ pathogenic, $4=$ likely pathogenic, $3=$ uncertain significance. Minor allele frequency of variants derived from the Exome Aggregation Consortium. Ref: reference allele; Alt: alternative allele; ClinVar: database of reported associations of variants to clinical phenotypes; CADD: combined annotation dependent depletion; REVEL: rare exome variant ensemble learner; MAF: minor allele frequency; ins: insertion; del: deletion.

Screening of those 17 genes among the population controls revealed 157 potentially damaging variants (Supplementary Table S1) of which 137 were only discovered in the control populations, giving a total of 168 potentially damaging variants. In total, 79 of these variants were known to be pathogenic or likely pathogenic according to ClinVar, while the remaining variants were considered potentially damaging due to their truncating effects on protein domains or by having a REVEL score $\geq 0.75$ and a CADD score $\geq 20$. Of the 168 potentially damaging variants, 47 were classified as Tier 1 variants and 121 as Tier 2 variants. In total, 21 of the 47 Tier 1 variants were stopgain, 16 were frameshift indels, and 10 were splicing site altering variants.

In exploring the final 168 variants among the 122 lethal cases, 15 men $(12.3 \%)$ carried at least one potentially damaging Tier 1 germline mutation in a DNA repair gene (one man carried two different Tier 1 mutations in the ATM gene), which was significantly higher than that observed in unselected cases $(0 \%, p=0.003$, Table 3$)$. 
Table 3. Carrier rates of potentially damaging mutations, stratified by Tier 1 and Tier 2 classification, in men with lethal prostate cancer, unselected prostate cancer, and population controls.

\begin{tabular}{|c|c|c|c|c|c|c|c|}
\hline & $\begin{array}{l}\text { Lethal PrCa } \\
\quad(n=122)\end{array}$ & $\begin{array}{c}\text { Unselected } \\
\text { PrCa }(n=60)\end{array}$ & $\begin{array}{c}p \\
\text { Value }\end{array}$ & $\begin{array}{l}\text { Finnish } \\
\text { Controls } \\
(n=3307)\end{array}$ & $\begin{array}{c}p \\
\text { Value }\end{array}$ & $\begin{array}{l}\text { Swedish } \\
\text { Controls } \\
(n=6192)\end{array}$ & $\begin{array}{c}p \\
\text { Value }\end{array}$ \\
\hline \multicolumn{8}{|l|}{ Tier 1} \\
\hline$E R C C 3, n(\%)$ & $1(0.82)$ & 0 & 1.000 & 0 & 0.036 & $3(0.05)$ & 0.075 \\
\hline$R A D 18, n(\%)$ & $1(0.82)$ & 0 & 1.000 & 0 & 0.036 & 0 & 0.019 \\
\hline ATM, n (\%) & $4(3.28)$ & 0 & 0.304 & $4(0.12)$ & $<0.001$ & $10(0.16)$ & $<0.001$ \\
\hline FANCM, $n(\%)$ & $2(1.64)$ & 0 & 1.000 & $89(2.69)$ & 0.772 & $44(0.71)$ & 0.223 \\
\hline NTHL1, $n(\%)$ & $2(1.64)$ & 0 & 1.000 & $24(0.73)$ & 0.236 & $39(0.63)$ & 0.187 \\
\hline CHEK $2, n(\%)$ & $5(4.10)$ & 0 & 0.173 & $60(1.81)$ & 0.080 & $5(0.08)$ & $<0.001$ \\
\hline All, $n(\%)$ & 15 (12.30) & 0 & 0.003 & 177 (5.35) & 0.004 & 101 (1.63) & $<0.001$ \\
\hline \multicolumn{8}{|l|}{ Tier 2} \\
\hline MUTYH,n (\%) & 0 & $1(1.67)$ & 0.330 & 34 (1.03) & 0.633 & $75(1.21)$ & 0.406 \\
\hline$E R C C 3, n(\%)$ & $1(0.82)$ & $1(1.67)$ & 0.552 & $5(0.15)$ & 0.195 & $4(0.06)$ & 0.093 \\
\hline$H L T F, n(\%)$ & $1(0.82)$ & 0 & 1.000 & $20(0.60)$ & 0.534 & $9(0.15)$ & 0.177 \\
\hline POLL, $n(\%)$ & $1(0.82)$ & 0 & 1.000 & $15(0.45)$ & 0.441 & $28(0.45)$ & 0.433 \\
\hline MRE11A, $n(\%)$ & $1(0.82)$ & 0 & 1.000 & 0 & 0.036 & 0 & 0.019 \\
\hline ATM, $n(\%)$ & $2(1.64)$ & 0 & 1.000 & $13(0.39)$ & 0.098 & $28(0.45)$ & 0.114 \\
\hline RECQL, $n(\%)$ & $1(0.82)$ & 0 & 1.000 & 0 & 0.036 & $13(0.21)$ & 0.239 \\
\hline FAN1, $n(\%)$ & $1(0.82)$ & 0 & 1.000 & $2(0.06)$ & 0.103 & $16(0.26)$ & 0.283 \\
\hline NEIL1, $n(\%)$ & $1(0.82)$ & 0 & 1.000 & $3(0.09)$ & 0.135 & $16(0.26)$ & 0.283 \\
\hline POLG, $n(\%)$ & $5(4.10)$ & 0 & 0.173 & $197(5.96)$ & 0.555 & $190(3.07)$ & 0.429 \\
\hline TP53, $n(\%)$ & $2(1.64)$ & 0 & 1.000 & $3(0.09)$ & 0.012 & $7(0.11)$ & 0.012 \\
\hline$B R C A 1, n(\%)$ & $1(0.82)$ & 0 & 1.000 & $2(0.06)$ & 0.103 & $5(0.08)$ & 0.111 \\
\hline RECQL5, $n(\%)$ & $1(0.82)$ & 0 & 1.000 & $3(0.09)$ & 0.135 & $1(0.02)$ & 0.038 \\
\hline CHEK2, $n(\%)$ & $1(0.82)$ & $1(1.67)$ & 0.552 & $2(0.06)$ & 0.103 & $28(0.45)$ & 0.433 \\
\hline All, $n(\%)$ & $16(13.11)$ & $3(5.00)$ & 0.123 & $299(9.04)$ & 0.148 & $420(6.78)$ & 0.011 \\
\hline
\end{tabular}

PrCa: prostate cancer. P value: the frequency of potentially damaging DNA repair gene mutation carriers among the lethal PrCa patients was compared to the frequency in unselected PrCa patients and the two control populations with the use of a two-sided Fisher's exact test.

No significant difference in the Tier 1 mutation carrier rate was observed between Swedish (13.3\%) and Finnish $(10.6 \%, p=0.781)$ lethal cases. The two most frequently mutated genes were CHEK2 $(4.1 \%)$ and ATM (3.3\%, Table 3, Figure 2). The observed carrier rate of Tier 1 mutations was significantly higher in the lethal cases compared to the prevalence in the Swedish $(1.6 \%, p<0.001)$ and the Finnish $(5.4 \%, p=0.040)$ population controls.

The observed carrier rate of potentially damaging Tier 2 germline mutations was higher in the lethal cases (13.1\%) compared to that of the unselected cases (5.0\%); however, the difference was not statistically significant $(p=0.123$, Table 3$)$. Compared to Swedish controls $(6.8 \%, p=0.011)$, a higher mutation rate was observed among the lethal cases; however, there was no statistically significant difference in the carrier rate of Tier 2 mutations between the lethal cases and the Finnish population controls $(9.0 \%, p=0.148)$. No significant difference in the Tier 2 mutation carrier rate was observed between Swedish and Finnish lethal cases $(p=0.102)$.

No potentially damaging variants, neither Tier 1 nor Tier 2, were observed in the $B R C A 2$ gene in any of the PrCa cases. In the population controls, we observed a carrier rate of Tier 1 BRCA2 mutations of $0.68 \%$ and $0.64 \%$ in Sweden and Finland, respectively. 


\section{Variant type}

Frameshift indel

Missense

Stopgain

Splicing site

Non-frameshift indel

\section{Cohort}

- Finnish/Swedish cohort

A Previously reported

\section{CHEK2 (NM145862)}

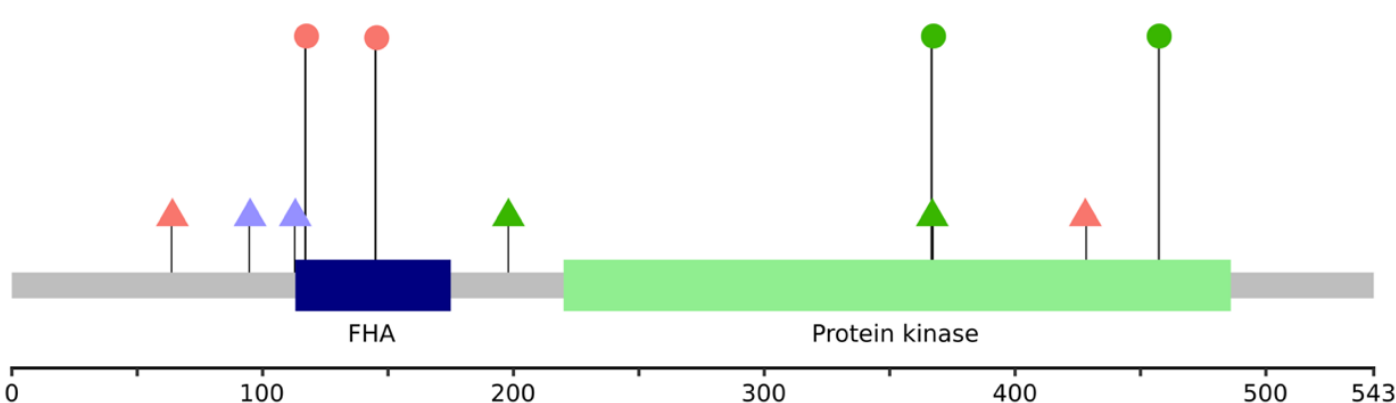

AA Position

\section{ATM (NM000051)}

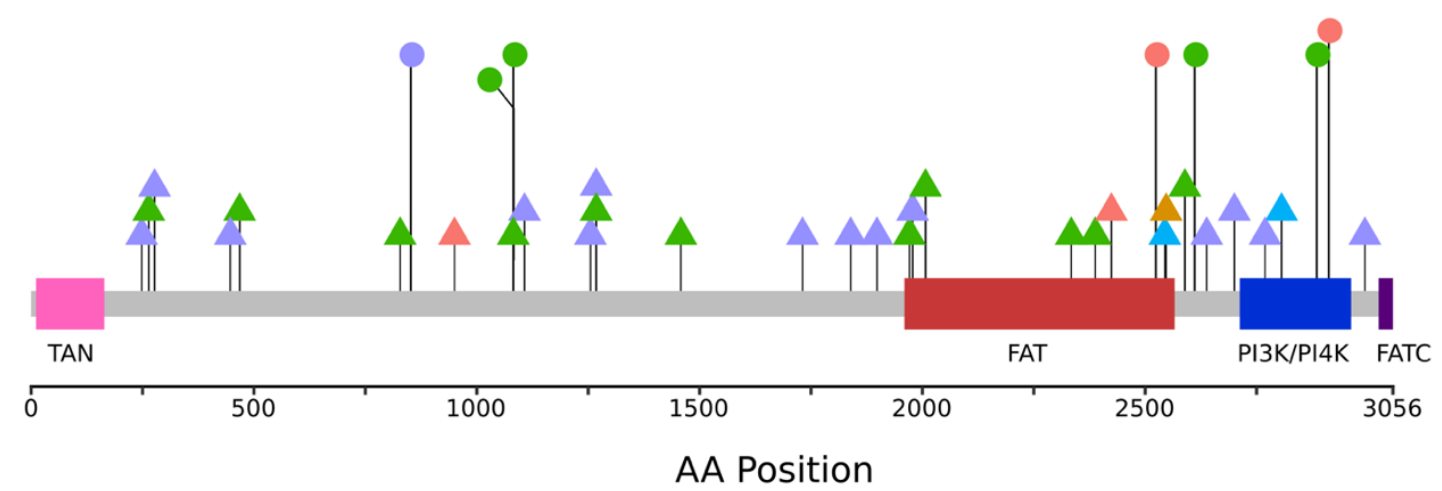

Figure 2. Potentially damaging variants found in the CHEK2 and ATM genes. Locations of variants are shown as lollipop structures. The variants found in the Finnish/Swedish lethal or unselected cases are indicated by circles, and variants found in selected previous studies $[7,11,18,28]$ are indicated by triangles. The variant type is indicated by the color.

\section{Discussion}

In this study, we characterized the germline variants occurring in the DNA repair pathway from 122 lethal and 60 unselected PrCa patients. In total, 16 potentially damaging protein truncating variants (Tier 1$)$ were identified in 15 men (12.3\%) among the lethal cases significantly exceeding the carrier rate of $0 \%$ in the unselected cases as well as the population prevalence of $1.6 \%$ and $5.4 \%$ in Swedish and Finnish population controls. In contrast, the frequency of potentially damaging nonsynonymous 
single nucleotide variants (Tier 2) showed similar frequencies among lethal cases, unselected cases and population controls.

Previous studies focusing on aggressive and metastatic PrCa cases have found higher frequencies of deleterious germline variants in $B R C A 2$ than in any other DNA repair gene and thus considered it to be the major contributor among DNA repair genes to the aggressive phenotype $[7,11,29]$. However, we observed a frequency of zero pathogenic $B R C A 2$ variants in our lethal cases, suggesting that $B R C A 2$ does not play a major role in aggressive and lethal PrCa in the Swedish and Finnish populations. This agrees with earlier studies in which $B R C A 1$ and $B R C A 2$ were not found to have a significant contribution to PrCa susceptibility or aggressiveness in Finland or Sweden [30,31]. In a recent study by Mayrhofer and coworkers, sequencing of 217 metastatic PrCa cases from Sweden revealed only two pathogenic BRCA2 mutation carriers (0.93\% carrier rate, [31]). Assuming the same carrier rate among our lethal cases, we would expect to find, on average, 1.1 carriers of $B R C A 2$ mutations in our study, and our null finding is therefore not surprising. In general, the frequencies of established prostate cancer susceptibility variants deviate from population to population. One such case is the known cancer susceptibility variant G84E in HOXB13, which has been shown to have a mutation frequency approximately three-fold higher in Sweden and Finland compared to the mutation frequency in North America [32-34].

ATM and its role in pancreatic cancer was recently reviewed [35] and germline mutations in ATM have been associated with predisposition for several cancer forms [36] including PrCa [3]. Several studies have particularly reported potentially damaging variants in ATM in aggressive $\operatorname{PrCa}$ cases $[7,9,29,31]$. We also found high frequencies of potentially damaging variants in our lethal cohort (3.28\% and $1.64 \%$ for Tier 1 and 2 variants, respectively), while in the unselected cases, the frequencies of these variants were found to be very low, similar to those of the population controls. These data support the evidence that deleterious variants in ATM are associated with the lethal phenotype of the disease. ATM is known to have a predominant role in the DNA damage response, but it also plays a role in maintaining the overall functionality of the cell [37]. ATM mutations that cause its inactivation or deficiency have shown a variety of pathological manifestations, including oxidative stress, metabolic syndrome, mitochondrial dysfunction and neurodegeneration. Recently ATM deficiency was shown to promote the progression of castration-resistant PrCa by enhancing the Warburg effect, suggesting that ATM mutation contributes through a metabolic-in addition to DNA repair-mechanism [38].

CHEK2 variants have been associated with PrCa predisposition in several studies $[9,10]$, and we found that this gene was the most frequently mutated Tier 1 gene in our study (4.1\%). In a recent study of 217 metastatic PrCa patients from Sweden [31], CHEK2 was also the most frequently mutated DNA repair gene (3.8\%), highlighting the importance of CHEK2 mutations for aggressive PrCa in the Nordic population. Of note, in both the present study and the study by Mayrhofer and coworkers [31], c.1100delC was the most commonly observed mutation in CHEK2 (3.2\% and $1.9 \%$, respectively). $\mathrm{Wu}$ and coworkers also assessed the frequencies of potentially damaging CHEK2 variants in lethal cases and in cases with localized low-risk PrCa from the US [39]. Overall, no association was found between CHEK2 mutation status and lethal disease, but one variant, c.1100delC, was found to have a significantly higher frequency in the lethal cases $(1.3 \%)$ compared to that of the low-risk PrCa patients $(0.2 \%, p=0.004)$, supporting the importance of this mutation for lethal PrCa. The c.1100delC has been shown to trigger nonsense-mediated mRNA decay, and subsequent protein analyses suggested that the truncated protein is likely highly unstable [40]. No mechanistic data are available for $\operatorname{PrCa}$, but patients with CHEK2 mutations are among those showing a high response rate to treatment with the poly-ADP ribose polymerase inhibitor Olaparib when cancers were no longer responding to standard treatments [41].

Of note, only heterozygous carriers of protein-truncating variants were observed in our study conforming to the classical two-hit model for tumor suppressor genes [42,43]. No novel candidate genes within the DNA repair pathway were found in our study. The lack of novel findings is not surprising considering the limited sample size of the study. Moreover, we applied a relatively strict 
approach for prioritizing variants, which may have led us to underestimate the role of some genes or even to completely miss potential candidate genes.

We pooled Finnish and Swedish lethal cases to improve the statistical power of the association analysis. No adjustment for possible confounding, for example by population stratification, PSA screening history or family history of $\mathrm{PrCa}$, was performed. Population stratification is always of importance in genetic association studies. However, genotypes from genome-wide single nucleotide polymorphisms were not available for all cases and we were therefore not able to adjust for possible population stratification through principal components in the current study. PSA screening is known to decrease PrCa-specific mortality $[44,45]$ and it is possible that screening history may have confounded our analysis. However, for this to be the case PSA screening history must be associated with carrying pathogenic mutations in DNA repair genes which we find unlikely. Finally, Pritchard and coworkers [11] reported that deleterious mutation frequencies of DNA repair genes did not differ according to whether a family history of PrCa was present among 692 men with metastatic PrCa. Therefore, we argue that confounding by family history is of limited concern in our study.

\section{Conclusions}

In conclusion, germline variants in DNA repair genes have been shown to be associated with the aggressive form of $\mathrm{PrCa}-\mathrm{a}$ finding that is supported by our study. Unlike previous studies, we did not observe high numbers of potentially damaging germline variants in BRCA2. Instead, mutations in $A T M$ and CHEK2 were found to be most frequent among the lethal cases, highlighting the importance of the population-specific assessment of the variants contributing to the aggressiveness of PrCa.

Supplementary Materials: The following are available online at http://www.mdpi.com/2073-4425/11/3/314/s1, Table S1: Potentially damaging variants discovered in control populations.

Author Contributions: Conceptualization, T.W., J.S. and F.W.; Data curation, T.R. and J.L.; Formal analysis, T.R. and F.W.; Funding acquisition, F.W.; Investigation, J.S. and F.W.; Methodology, T.R., J.L. and M.N.; Project administration, A.K., C.H. and J.L.; Resources, T.W., A.K., C.H., J.L., T.L.J.T., J.S. and F.W.; Software, T.R. and F.W.; Supervision, J.S. and F.W.; Validation, J.S. and F.W.; Visualization, J.S. and F.W.; Writing-original draft, T.R.; Writing-review and editing, T.R., J.S. and F.W. All authors have read and agreed to the published version of the manuscript.

Funding: This research was funded by the Sigrid Juselius Foundation (to J.S.), the Academy of Finland (\#251074 and \#310115 to J.S.), the Cancer Foundation Finland (to J.S. and T.R.), the National Cancer Institute Grant U01 CA 89600 (support for the ICPCG), the Tampere Graduate Program in Biomedicine and Biotechnology (to T.R.), the Swedish Cancer Society (CAN 2016/818), and the Nordic Cancer Union.

Acknowledgments: Kirsi Rouhento is thanked for her assistance.

Conflicts of Interest: The authors declare no conflict of interest.

\section{References}

1. Siegel, R.L.; Miller, K.D.; Jemal, A. Cancer statistics, 2019. CA Cancer J. Clin. 2019, 69, 7-34. [CrossRef] [PubMed]

2. Mucci, L.A.; Hjelmborg, J.B.; Harris, J.R.; Czene, K.; Havelick, D.J.; Scheike, T.; Graff, R.E.; Holst, K.; Moller, S.; Unger, R.H.; et al. Familial risk and heritability of cancer among twins in nordic countries. JAMA 2016, 315, 68-76. [CrossRef] [PubMed]

3. Schumacher, F.R.; Al Olama, A.A.; Berndt, S.I.; Benlloch, S.; Ahmed, M.; Saunders, E.J.; Dadaev, T.; Leongamornlert, D.; Anokian, E.; Cieza-Borrella, C.; et al. Association analyses of more than 140,000 men identify 63 new prostate cancer susceptibility loci. Nat. Genet. 2018, 50, 928-936. [CrossRef] [PubMed]

4. Szulkin, R.; Karlsson, R.; Whitington, T.; Aly, M.; Gronberg, H.; Eeles, R.A.; Easton, D.F.; Kote-Jarai, Z.; Al Olama, A.A.; Benlloch, S.; et al. Genome-wide association study of prostate cancer-specific survival. Cancer Epidemiol. Biomark. Prev. 2015, 24, 1796-1800. [CrossRef]

5. Jeggo, P.A.; Pearl, L.H.; Carr, A.M. DNA repair, genome stability and cancer: A historical perspective. Nat. Rev. Cancer 2016, 16, 35-42. [CrossRef] 
6. Friedenson, B. The BRCA1/2 pathway prevents hematologic cancers in addition to breast and ovarian cancers. BMC Cancer 2007, 7, 152. [CrossRef]

7. Mijuskovic, M.; Saunders, E.J.; Leongamornlert, D.A.; Wakerell, S.; Whitmore, I.; Dadaev, T.; Cieza-Borrella, C.; Govindasami, K.; Brook, M.N.; Haiman, C.A.; et al. Rare germline variants in DNA repair genes and the angiogenesis pathway predispose prostate cancer patients to develop metastatic disease. Br. J. Cancer 2018, 119, 96-104. [CrossRef]

8. Kote-Jarai, Z.; Jugurnauth, S.; Mulholland, S.; Leongamornlert, D.A.; Guy, M.; Edwards, S.; Tymrakiewitcz, M.; O'Brien, L.; Hall, A.; Wilkinson, R.; et al. A recurrent truncating germline mutation in the BRIP1/FANCJ gene and susceptibility to prostate cancer. Br. J. Cancer 2009, 100, 426-430. [CrossRef]

9. Paulo, P.; Maia, S.; Pinto, C.; Pinto, P.; Monteiro, A.; Peixoto, A.; Teixeira, M.R. Targeted next generation sequencing identifies functionally deleterious germline mutations in novel genes in early-onset/familial prostate cancer. PLoS Genet. 2018, 14, e1007355. [CrossRef]

10. Seppala, E.H.; Ikonen, T.; Mononen, N.; Autio, V.; Rokman, A.; Matikainen, M.P.; Tammela, T.L.; Schleutker, J. CHEK2 variants associate with hereditary prostate cancer. Br. J. Cancer 2003, 89, 1966-1970. [CrossRef]

11. Pritchard, C.C.; Mateo, J.; Walsh, M.F.; De Sarkar, N.; Abida, W.; Beltran, H.; Garofalo, A.; Gulati, R.; Carreira, S.; Eeles, R.; et al. Inherited DNA-Repair Gene Mutations in Men with Metastatic Prostate Cancer. N. Engl. J. Med. 2016, 375, 443-453. [CrossRef] [PubMed]

12. Schleutker, J.; Matikainen, M.; Smith, J.; Koivisto, P.; Baffoe-Bonnie, A.; Kainu, T.; Gillanders, E.; Sankila, R.; Pukkala, E.; Carpten, J.; et al. A genetic epidemiological study of hereditary prostate cancer (HPC) in Finland: Frequent HPCX linkage in families with late-onset disease. Clin. Cancer Res. 2000, 6, 4810-4815. [PubMed]

13. Lindmark, F.; Zheng, S.L.; Wiklund, F.; Bensen, J.; Balter, K.A.; Chang, B.; Hedelin, M.; Clark, J.; Stattin, P.; Meyers, D.A.; et al. H6D polymorphism in macrophage-inhibitory cytokine-1 gene associated with prostate cancer. J. Natl. Cancer Inst. 2004, 96, 1248-1254. [CrossRef] [PubMed]

14. Li, H.; Durbin, R. Fast and accurate short read alignment with Burrows-Wheeler transform. Bioinformatics 2009, 25, 1754-1760. [CrossRef] [PubMed]

15. Quinlan, A.R. BEDTools: The swiss-army tool for genome feature analysis. Curr. Protoc. Bioinform. 2014, 47, 11-12. [CrossRef] [PubMed]

16. PICARD. Available online: http://broadinstitute.github.io/picard/ (accessed on 6 February 2019).

17. McKenna, A.; Hanna, M.; Banks, E.; Sivachenko, A.; Cibulskis, K.; Kernytsky, A.; Garimella, K.; Altshuler, D.; Gabriel, S.; Daly, M.; et al. The genome analysis toolkit: A mapreduce framework for analyzing next-generation DNA sequencing data. Genome Res. 2010, 20, 1297-1303. [CrossRef] [PubMed]

18. DePristo, M.A.; Banks, E.; Poplin, R.; Garimella, K.V.; Maguire, J.R.; Hartl, C.; Philippakis, A.A.; del Angel, G.; Rivas, M.A.; Hanna, M.; et al. A framework for variation discovery and genotyping using next-generation DNA sequencing data. Nat. Genet. 2011, 43, 491-498. [CrossRef]

19. Van der Auwera, G.A.; Carneiro, M.O.; Hartl, C.; Poplin, R.; Del Angel, G.; Levy-Moonshine, A.; Jordan, T.; Shakir, K.; Roazen, D.; Thibault, J.; et al. From FastQ data to high confidence variant calls: The genome analysis toolkit best practices pipeline. Curr. Protoc. Bioinform. 2013, 43, 11.10.1-11.10.33. [CrossRef]

20. Wang, K.; Li, M.; Hakonarson, H. ANNOVAR: Functional annotation of genetic variants from high-throughput sequencing data. Nucleic Acids Res. 2010, 38, e164. [CrossRef]

21. Lange, S.S.; Takata, K.; Wood, R.D. DNA polymerases and cancer. Nat. Rev. Cancer 2011, 11, 96-110. [CrossRef]

22. Wood, R.D.; Mitchell, M.; Lindahl, T. Human DNA repair genes, 2005. Mutat. Res. 2005, 577, $275-283$. [CrossRef] [PubMed]

23. Wood, R.D.; Mitchell, M.; Sgouros, J.; Lindahl, T. Human DNA repair genes. Science 2001, 291, 1284-1289. [CrossRef] [PubMed]

24. Kircher, M.; Witten, D.M.; Jain, P.; O’Roak, B.J.; Cooper, G.M.; Shendure, J. A general framework for estimating the relative pathogenicity of human genetic variants. Nat. Genet. 2014, 46, 310-315. [CrossRef] [PubMed]

25. Ioannidis, N.M.; Rothstein, J.H.; Pejaver, V.; Middha, S.; McDonnell, S.K.; Baheti, S.; Musolf, A.; Li, Q.; Holzinger, E.; Karyadi, D.; et al. REVEL: An ensemble method for predicting the pathogenicity of rare missense variants. Am. J. Hum. Genet. 2016, 99, 877-885. [CrossRef] [PubMed] 
26. UniProt, C. UniProt: A worldwide hub of protein knowledge. Nucleic Acids Res 2019, 47, D506-D515. [CrossRef]

27. Lek, M.; Karczewski, K.J.; Minikel, E.V.; Samocha, K.E.; Banks, E.; Fennell, T.; O’Donnell-Luria, A.H.; Ware, J.S.; Hill, A.J.; Cummings, B.B.; et al. Analysis of protein-coding genetic variation in 60,706 humans. Nature 2016, 536, 285-291. [CrossRef]

28. Hart, S.N.; Ellingson, M.S.; Schahl, K.; Vedell, P.T.; Carlson, R.E.; Sinnwell, J.P.; Barman, P.; Sicotte, H.; Eckel-Passow, J.E.; Wang, L.; et al. Determining the frequency of pathogenic germline variants from exome sequencing in patients with castrate-resistant prostate cancer. BMJ Open 2016, 6, e010332. [CrossRef]

29. Na, R.; Zheng, S.L.; Han, M.; Yu, H.; Jiang, D.; Shah, S.; Ewing, C.M.; Zhang, L.; Novakovic, K.; Petkewicz, J.; et al. Germline Mutations in ATM and BRCA1/2 Distinguish Risk for Lethal and Indolent Prostate Cancer and are Associated with Early Age at Death. Eur. Urol. 2017, 71, 740-747. [CrossRef]

30. Ikonen, T.; Matikainen, M.P.; Syrjakoski, K.; Mononen, N.; Koivisto, P.A.; Rokman, A.; Seppala, E.H.; Kallioniemi, O.P.; Tammela, T.L.; Schleutker, J. BRCA1 and BRCA2 mutations have no major role in predisposition to prostate cancer in Finland. J. Med. Genet. 2003, 40, e98. [CrossRef]

31. Mayrhofer, M.; De Laere, B.; Whitington, T.; Van Oyen, P.; Ghysel, C.; Ampe, J.; Ost, P.; Demey, W.; Hoekx, L.; Schrijvers, D.; et al. Cell-free DNA profiling of metastatic prostate cancer reveals microsatellite instability, structural rearrangements and clonal hematopoiesis. Genome Med. 2018, 10, 85. [CrossRef]

32. Ewing, C.M.; Ray, A.M.; Lange, E.M.; Zuhlke, K.A.; Robbins, C.M.; Tembe, W.D.; Wiley, K.E.; Isaacs, S.D.; Johng, D.; Wang, Y.; et al. Germline mutations in HOXB13 and prostate-cancer risk. N. Engl. J. Med. 2012, 366, 141-149. [CrossRef] [PubMed]

33. Laitinen, V.H.; Wahlfors, T.; Saaristo, L.; Rantapero, T.; Pelttari, L.M.; Kilpivaara, O.; Laasanen, S.L.; Kallioniemi, A.; Nevanlinna, H.; Aaltonen, L.; et al. HOXB13 G84E mutation in Finland: Population-based analysis of prostate, breast, and colorectal cancer risk. Cancer Epidemiol. Biomark. Prev. 2013, 22, 452-460. [CrossRef] [PubMed]

34. Xu, J.; Lange, E.M.; Lu, L.; Zheng, S.L.; Wang, Z.; Thibodeau, S.N.; Cannon-Albright, L.A.; Teerlink, C.C.; Camp, N.J.; Johnson, A.M.; et al. HOXB13 is a susceptibility gene for prostate cancer: Results from the International Consortium for Prostate Cancer Genetics (ICPCG). Hum. Genet. 2013, 132, 5-14. [CrossRef] [PubMed]

35. Nanda, N.; Roberts, N.J. ATM serine/threonine kinase and its role in pancreatic risk. Genes 2020, 11, 108. [CrossRef] [PubMed]

36. Choi, M.; Kipps, T.; Kurzrock, R. ATM mutations in cancer: Therapeutic implications. Mol. Cancer Ther. 2016, 15, 1781-1791. [CrossRef] [PubMed]

37. Guleria, A.; Chandna, S. ATM kinase: Much more than a DNA damage responsive protein. DNA Repair (Amst) 2016, 39, 1-20. [CrossRef]

38. Xu, L.; Ma, E.; Zeng, T.; Zhao, R.; Tao, Y.; Chen, X.; Groth, J.; Liang, C.; Hu, H.; Huang, J. ATM deficiency promotes progression of CRPC by enhancing Warburg effect. Endocr. Relat. Cancer 2019, 26, 59-71. [CrossRef]

39. Wu, Y.; Yu, H.; Zheng, S.L.; Na, R.; Mamawala, M.; Landis, T.; Wiley, K.; Petkewicz, J.; Shah, S.; Shi, Z.; et al. A comprehensive evaluation of CHEK2 germline mutations in men with prostate cancer. Prostate 2018, 78, 607-615. [CrossRef]

40. Anczukow, O.; Ware, M.D.; Buisson, M.; Zetoune, A.B.; Stoppa-Lyonnet, D.; Sinilnikova, O.M.; Mazoyer, S. Does the nonsense-mediated mRNA decay mechanism prevent the synthesis of truncated BRCA1, CHK2, and p53 proteins? Hum. Mutat. 2008, 29, 65-73. [CrossRef]

41. Mateo, J.; Carreira, S.; Sandhu, S.; Miranda, S.; Mossop, H.; Perez-Lopez, R.; Nava Rodrigues, D.; Robinson, D.; Omlin, A.; Tunariu, N.; et al. DNA-Repair defects and olaparib in metastatic prostate cancer. N. Engl. J. Med. 2015, 373, 1697-1708. [CrossRef]

42. Knudson, A.G., Jr. Mutation and cancer: Statistical study of retinoblastoma. Proc. Natl. Acad. Sci. USA 1971, 68, 820-823. [CrossRef] [PubMed]

43. Wang, L.H.; Wu, C.F.; Rajasekaran, N.; Shin, Y.K. Loss of tumor suppressor gene function in human cancer: An overview. Cell Physiol. Biochem. 2018, 51, 2647-2693. [CrossRef] [PubMed] 
44. Schroder, F.H.; Hugosson, J.; Roobol, M.J.; Tammela, T.L.; Ciatto, S.; Nelen, V.; Kwiatkowski, M.; Lujan, M.; Lilja, H.; Zappa, M.; et al. Screening and prostate-cancer mortality in a randomized European study. N. Engl. J. Med. 2009, 360, 1320-1328. [CrossRef] [PubMed]

45. Schroder, F.H.; Hugosson, J.; Roobol, M.J.; Tammela, T.L.; Zappa, M.; Nelen, V.; Kwiatkowski, M.; Lujan, M.; Maattanen, L.; Lilja, H.; et al. Screening and prostate cancer mortality: Results of the European randomised study of screening for prostate cancer (ERSPC) at 13 years of follow-up. Lancet 2014, 384, 2027-2035. [CrossRef]

(C) 2020 by the authors. Licensee MDPI, Basel, Switzerland. This article is an open access article distributed under the terms and conditions of the Creative Commons Attribution (CC BY) license (http://creativecommons.org/licenses/by/4.0/). 